\title{
Kültür ve Etkinlik Turizmi Bağlamında Şaman Ritüelleri
}

\author{
Dr. Ümit ŞENGEL \\ Sakarya Uygulamalı Bilimler Üniversitesi, Turizm Fakültesi \\ umitsengel@gmail.com \\ https://orcid.org/0000-0003-1284-836X \\ DOI: https://doi.org/10.37847/tdtad.837297 \\ Makale Gönderim Tarihi: 07.12.2020 \\ Makale Türü: Araştırma Makalesi \\ Makale Kabul Tarihi: 26.12.2020
}

\section{Özet}

$\mathrm{Bu}$ çalışmada şaman ritüellerinin kültür ve etkinlik turizmi bağlamında incelenmesi amaçlanmaktadır. Milenyumla birlikte turizm endüstrisi ve buna bağlı olarak uluslararası seyahat hareketleri artmıştır. Bu artışın en önemli kaynağı ise istekleri sürekli değişen dinamik bir talebin olmasıdır. Destinasyonlar uygun arz kaynaklarını oluşturarak bu dinamik talebe cevap vermeye çalışmaktadır. Dünyanın küreselleşme süreciyle birlikte entegre olup standardize bir görüntü alması eski, geleneksel ve otantik olan değerlere yönelik merakı ve ilgiyi arttırmıştır. Bu kapsamda eski, geleneksel ve otantik bir inanç sisteminin uygulamalarını içeren şaman ritüellerinin de turizm faaliyetlerinin önemli bir kaynağı haline geldiği söylenebilir. Kavramsal incelemeye dayanan bu çalışmanın sonuçlarına göre, Şamanik turizm diye bir kavramın varlığı söz konusudur. Bu turizm çeşidinde turistler aldıkları bazı maddelerin etkisiyle halüsinasyon haline girerek şaman ile birlikte ritüellerin bir parçası haline gelmektedir. Bununla birlikte kültürel temsil yönü güçlü olan şaman ritüellerinin birer aktivite olarak turistler tarafindan izlendiği örnekleri de mevcuttur. Bu yöntemin dünya genelinde yaygınlık kazanacağı tahmin edilmektedir.

Anahtar Kelimeler: Kültür, Etkinlik Turizmi, Şaman Ritüelleri, Şamanik Turizm.

\section{Shaman Rituals in the Context of Culture and Event Tourism}

\begin{abstract}
The aim of this study is to examine shaman rituals in the context of culture and activity tourism. After the millennium, the tourism industry and, accordingly, international travel arrives are increasing. The most important source of this increase is dynamic demand whose demands are constantly changing. Destinations strive to respond to this dynamic demand by creating appropriate sources of supply. The fact that the world is integrated with the globalization process and has a standardized image has increased curiosity and interest in values that are old, traditional and authentic. In this context, it can be said that Shaman rituals, which include the practices of an ancient, traditional and authentic belief system, have also become an important source of tourism activities. According to the results of this study, which is based on conceptual analysis, there is a concept called shamanic tourism. In this tourism type, tourists become a part of the rituals with the shaman by hallucinating with the effects of some substances they take. However, there are also examples where shaman rituals, which have a strong cultural representation aspect, are observed by tourists as activities. It is estimated that this method will become widespread throughout the world.
\end{abstract}

Keywords: Culture, Event Tourism, Shaman Rituals, Shamanic Tourism. 


\section{GIRIŞ}

Seyahat olgusu insanlığın tarihi kadar eski olsa da, 18. yüzyıla kadarki seyahatler daha çok ticaret, keşif, merak gibi zorunlu veya sınırlı bireysel motivasyonlardan oluşmuştur. Günümüzdeki anlamıyla gezme, görme, eğlenme veya kendini yenileme gibi motivasyonlarla yapılan modern turizm hareketlerinin doğuşu sanayi devrimi sonrasına dayanmaktadır. Özellikle sanayi devrimi sonrasında ortaya çıkan makinelerin üretimde kullanılması kitle üretimini arttırmış, bu gelişme modern turizm hareketlerinin en önemli kaynaklarından olan boş zaman ve harcanabilir gelir gibi olguların artışını sağlamıştır (Can, 2015; Bakır ve Çelik, 2020). Makinelerin üretimde kullanılması emeğin (insanın) zaman kazanmasını sağlarken, artan kitle üretim gelirleri artırmıştır.

Süreç içerisinde dünya üzerinde giderek yaygın bir hale gelen modern turizm hareketleri uzun süre kitle turizminin yaygın olarak kullanıldığı bir kimlikle değerlendirilmiştir. Deniz, kum ve güneş gibi kaynakları kullanan kitle turizmi bu kaynaklara sahip destinasyonlar için turizmin önemli bir ekonomik aktör olarak ön plana çıkmasını sağlamıştır. 20 yüzyılın ortalarından sonra mevcut fiili durum devam etse de, turizm pazarının büyümesi, turizm endüstrisinin sahip olduğu ekonomik potansiyel ve insanların turizm hareketlerine karşı artan ilgisi kitle turizmine alternatif turizm kaynakları ve alternatif turizm türlerinin gelişimini hızlandırmıştır. Bu sayede ülkeler veya bölgeler kaynak üretmeye başlamış ve benzerlerinden farklılaşarak rekabet avantajı elde etmek için de mücadele etmeye başlamıştır.

Kültürel kaynaklar ve bu bağlamda da kültür turizmi kitle turizminin yaygınlığının farklı bir boyutta değerlendirilmesine zemin hazırlamıştır. Böylece toplumsal yapıyı oluşturan her türlü kültürel farklılık veya zenginlik turizm hareketlerine kaynak oluşturmaya başlamıştır (Toskay, 1993). Tarihi ve kültürel çekicilikler en önemli destinasyon çekim unsurları arasında yerini almaya başlamıştır. Çünkü insanlar kendilerinden farklı olan her türlü kültürel öğeyi merak etmiş ve merakını gidermek için seyahat hareketlerine katılmıştır. Böylece turizme kaynaklık eden kültür temelli bir etkileşim süreci ortaya çıkmıştır.

Aile yaşamı, mutfak, gelenekler, din veya inanç sistemleri gibi her türlü toplumsal kaynağın öğeleri kültür turizmine hizmet etmektedir. Turistik destinasyonlar etkinlikler düzenleyerek turistlere kültürel değerlerini tanıtma yoluna gitmektedir. Dolaysıyla son yıllarda etkinlik turizmi önemini giderek artırmaktadır. Özellikle etkinliklere kaynak oluşturabilecek kültürel öneme sahip ürün veya ritüellerin olması destinasyonların başarılarını olumlu düzeyde etkileyecek ürünlerin ortaya çıkmasına kaynaklık etmektedir.

$\mathrm{Bu}$ çalışmada Şamanizm ritüellerinin kültür ve etkinlik turizmi bağlamında incelenmesi amaçlanmaktadır. Eski dönem Asya toplumlarının önemli inançlarından olan Şamanizm'e ait bazı ritüellerin günümüze kadar geldiği bilinmektedir. Modern zamana uygun olarak şekil değiştiren ritüeller, turistler tarafından oldukça ilgi görmektedir. Bazı destinasyonlar turist çekmek için önemli bir alternatif kaynak olarak Şamanizm ritüellerinden oluşan etkinlikler düzenlemektedir. Bu bilgiler 1şığında, yapılan bu çalışmanın farklı konular arasındaki ilişkileri bütüncül bir bakış açısıyla ele alması nedeniyle ilgili alan yazına katkı sağlayacağı düşünülmektedir.

\section{KÜLTÜR-TURIZM ETKILEŞIMI VE KÜLTÜR TURIZMI}

Kültür kavramının epistemolojisi dikkate alındığında, kavramın tarih boyunca farklı anlamlara gelecek şekilde kullanıldığı görülmektedir. Latince "cultura" kelimesinden gelen ve 15. yüzyıldan itibaren İngilizce'ye geçen kavramın ilk kullanımlarda süreç anlamında kullanıldığı bilinmektedir. Tarih içerisinde değişik anlamlarda kullanılsa da, günümüze doğru toplumlara ait özgül ve değişken özellikleri tanımlamak için kullanılmaktadır. Bu toplumlar yerel düzeyde olduğu gibi ulusal 
düzeyde de olabilmektedir (Williams, 2018). İnsan için yaşadığı yerlerin farklılaşması, yaşam biçimi ve kültürlerinin de farklılaşmasına neden olmaktadır. Doğa ve insan arasındaki etkileşim ve girilen yaşam mücadelesinin kazanılarak, yaşamın sürdürülebilir kılınma çabası çok farklı kültürlerin ortaya çıkıp gelişmesine zemin hazırlamıştır (Emekli, 2006). Bu gelişmeler birbirinden farklı çok yapılı "kültürler" olgusunun ortaya çıkıp gelişmesini hızlandırmıştır. Kültürün sahip olduğu mevcut anlam, kavramın turizm hareketlerine kaynak teşkil etmedeki önemini ortaya koymaktadır.

Kültür turizm pazarı, kitle turizminden sonra gelişim gösteren en önemli turizm kaynaklarından biri olarak ifade edilebilir. Bu turizm çeşidindeki somut büyüme insanların merakı, giderek artan eğitim seviyesi ve farklı deneyim arayışları gibi sebeplerle her geçen gün daha da artmaktadır. Çünkü turizm geleneksel kültürün yeniden inşasına katkıda bulunmakta ve yerel halkın gelirlerinde artışa neden olmaktadir (McKercher ve Du Cros, 2002).

Kültür turizminin gelişmesiyle birlikte tarihi nitelikte şehirlerin ön plana çıkma süreci hızlanmıştır. Eski ve tarihi yerleşim yerleri turizm sayesinde yenilenmektedir. Bu sayede eski yapılar tarihi değerlerini kaybetmeyecek (aslına uygun) şekilde restore edilmektedir. Geleneksel anlayışı modern bir konseptle sunan bu yapılar önemli birer turistik çekicilik haline gelmektedir (Kousis, 2000). Bu ve benzeri kültürel varlıkların turizme kazandırılması yerel halka ve kamu otoritelerine önemli kazanımlar sağlamaktadır. Tarihi ve kültürel kaynaklar bu sayede koruma altına alınabilmektedir. Bunun yanında, kültür turizmin gelişmesiyle birlikte hem turistler hem de yerel halkın kültürel değerlere ilişkin bilgi ve farkındalık sahibi oldukları söylenebilir (Huh, 2002).

Turizm ile kültür arasındaki etkileşim tek taraflı değildir. Bir yandan kültür turizm hareketleri için kaynak oluştururken, diğer yandan turizm faaliyetlerindeki artış kültürel değerlerin korunmasına aracılık etmektedir. Turizmin özellikle sosyal ve ekonomik kazanımları, kültürel değerleri koruma noktasında insanlara daha duyarlı hareket etmelerini sağlamıştır. İnsanların yaşam düzeylerinde meydana gelen iyileşmeler, toplum bilincinin gelişmesi, yeni iş olanakları gibi kazanımları turizmin kültürel mirasın korunmasına yönelik sosyo-ekonomik kimlik kazanmasını sağlamıştır. Kültürel miras ve kültürel kaynakları kullan turizm hareketleri ekonomik ve sosyal kazanımlar ve bu kapsamda değerlendirilebilecek olan sürdürülebilirlik gibi sebeplerle birbirlerine ihtiyaç duyan olgulardır (Akgül, 2003; Uygur ve Baykan, 2007).

$\mathrm{Bu}$ çalışmada olduğu gibi literatürün genelinde kültür turizmi son yıllarda artış eğilimi gösteren bir turizm çeşidi gibi ele alınsa da, kültür turizminin köken olarak modern turizme kaynaklık ettiği söylenebilir. Nitekim sanayi devrimi sonrasına denk gelen ve zengin İngiliz ailelerinin çocuklarını eğitim amacıyla farklı Avrupa ülkelerine göndermeleri sonucu ortaya çıkmış olan "Grand Tour"un modern turizm hareketleri ve kültür turizminin ilk örnekleri olarak ele alınabilir (Kozak, vd., 2013). Ancak, giderek yaygınlaşan farklı turizm türleri nedeniyle o günkü yapılan turun bugün kültür turizmi bağlamında ele alınması zor olabilirdi.

Turizmde 18. Yüzyılla birlikte görülen iyimser tablo 20. Yüzyılla birlikte dağılmaya başlamıştır. Bu yüzyılın ilk yarısına iki dünya savaşı ve bir ekonomik kriz (büyük buhran) sığdıran dünyada, insanlar en büyük çabayı sosyal, siyasal ve ekonomik meselelere harcamıştır. 2. Dünya savaşının sona ermesiyle birlikte, 20. yüzyılın ikinci yarısından sonra turizm hareketlerinde ciddi bir artış yaşanmıştır. Yaşanılan siyasi ve ekonomik gerginliklerden sonra insanlar büyük gruplar haline kitle turizmine katılmışlardır (Şengel, 2019). Kitle turizmi sonrası gelişen alternatif turizm türlerinden en önemlilerin başında ise kültür turizmi gelmektedir. 


\section{ETKİNLİK TURİMI}

Etkinlik turizmi kavramı, Etkinlikler aracılığıyla turizme katılan turistleri maksimum seviyeye çıkarmak için birincil/ikincil turistik çekim unsuru olarak etkinliklerin planlı bir şekilde geliştirilerek pazarlanması olarak tanımlanabilir (Getz, 1997). Tassiopoulos, (2005) kavramı destinasyonlarda turistik çekicilikler oluşturmak için bir dizi etkinliğin belli kullar dahilinde planlanması, geliştirilmesi, düzenlemesi ve pazarlanması şeklinde tanımlamaktadır. Kozak ve Bahçe (2009) bu iki tanımı destekleyici bir tanımlama yaparken, etkinlik turizmine konu olan etkinliğin özel bir olay olduğunu vurgulamaktadır. Bu sayede geleneksel ve tarihi yönü ön planda olan sosyo-kültürel olaylar etkinlik turizmi bağlamında yeniden şekillendirilerek yeni bir kimlikle turistik faaliyetler için bir çekicilik unsuruna dönüştürülmektedir.

İlgili tanımlarda esas üzerinde durulan konu etkinliklerin planlanması, geliştirilmesi, düzenlemesi ve pazarlanmasına ilişkin kısımdır. Çünkü bu öğeler aşağıda Şekil 1'de verilen etkinlik planlama modelinin boyutlarını oluşturmaktadır.

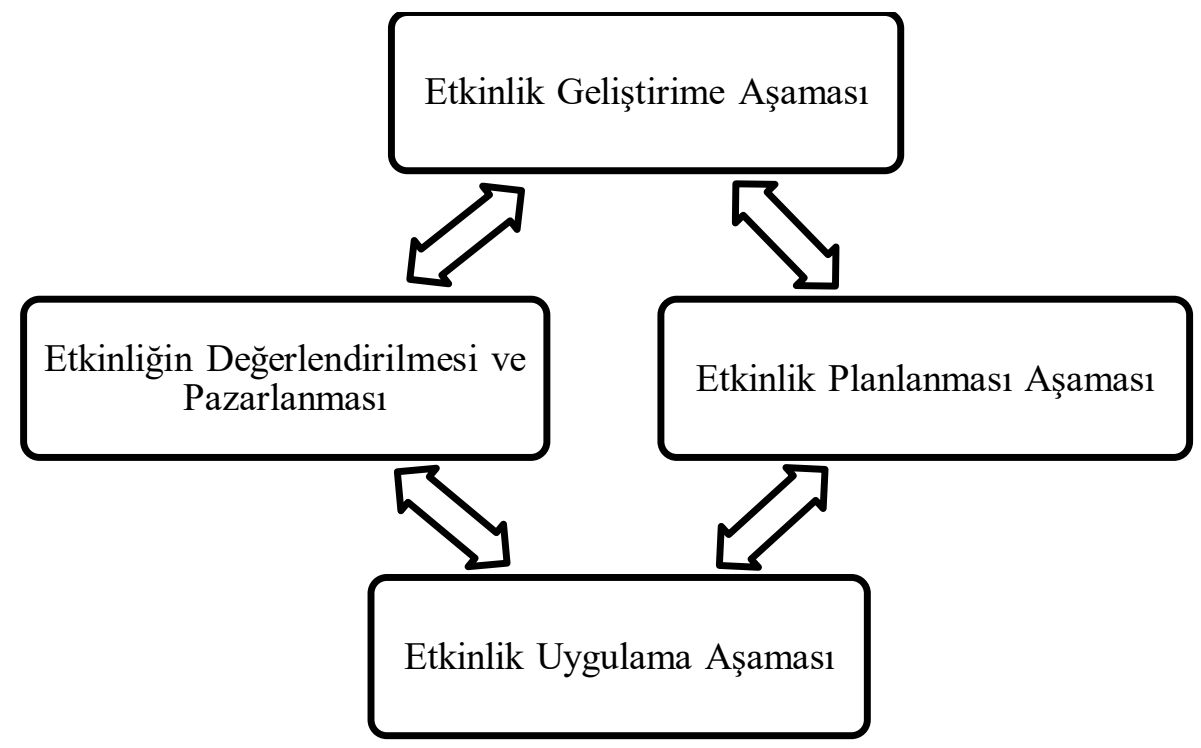

Şekil 1. Etkinlik Planlama Modeli

Kaynak: (Malen ve Adams, 2008)'den geliştirilmiştir.

Etkinlik turizminin giderek yaygınlık kazanmasında kentleşme olgusunun önemli etkileri vardır. Artan kentleșme oranı ve kırsal kesimlerden kentlileșme olgusuna karșı duyulan özlem kentleşmenin her geçen gün daha da artmasına neden olmaktadır. Bu artış turizm hareketlerinin artıșına da kaynaklık etmektedir. Artan kentsel mekânlar ve yoğun iş yaşamı insanların kent dıșı alanlarda vakit geçirme isteğini tetiklemektedir. Aynı zamanda kentlerde giderek azalan rekreasyonel alanlar da kent insanın kentin dışında kalan alanlara ilgisini arttırmaktadır (Şahin, vd., 2009; Akten ve Akten, 2011). Bu gelişmeler kentlerin dışında, kent insanın ihtiyaçlarına uygun rekreatif ve turistik kaynakların oluşturulmasına neden olmaktadır. Bu kaynakların başında etkinlikler gelmektedir. Destinasyonlar farklı etkinlikler düzenleyerek, etkinliğe ilgi duyan insanların destinasyonu ziyaret etmelerini sağlamaya çalışmaktadır. Sanat, kültür, spor, inanç, gastronomi temalı etkinlikler destinasyonların olumlu bir imaj geliştirerek turizm pazarından daha 
fazla pay almalarına aracılık etmektedir (Tayfun ve Arslan, 2013; Can, 2015). Etkinlik turizmi gerçekleştiği destinasyonlarda önemli kazanımlar sağladığı için destinasyonların pazarlanmasında etkin bir şekilde kullanılmaktadır. Etkinliklerin sahip olduğu olumlu yönler aşağıdaki gibi siralanabilir (Ery1lmaz ve Cengiz, 2012);

- Daha yüksek yaşam standard1

- Daha yüksek harcama

- Daha yüksek gelir ve artan para sirkülasyonu

- İstihdam yaratma ve spekülatif kazançlar

- Mülkiyet edinme teşviği ve kentsel dönüşüm

- Artan sermaye (yatırım)

- Yatırım firsatlarına teşvik

- Sponsorluklar yoluyla marka promosyonu

- Dünya çapında tanınma, imaj kazanma veya yenileme

- Bölge hakkındaki farkındalığın artması

- Turistik ürünlere değer katması ve ürün çeşitliliğinin artması

- Turistik ürünleri rakiplerden ayırma

- Bölgede yatırım ve ticaret potansiyeli hakkında bilginin artmas1

Kitle turizmine alternatif olması ve kültür turizmini kaynak olarak kullanması nedeniyle etkinlik turizminin destinasyonlara sağladığı en önemli kazanımların başında mevsimselliği ortadan kaldırması gerekmektedir. Gerçekleştirilen sezon dişı etkinliklerle destinasyonlarda turizm faaliyetlerinin yılın tamamına yayılması hedeflenmektedir. Çünkü etkinliklerin kaynağını deniz, kum ve güneş yerine yılın tamamında destinasyonun sahip olduğu sosyo-kültürel değerler oluşturmaktadır. Gerçekleştirilen etkinlikler, turistlerin alışılmışın dışında bir kültürel deneyim yaşamalarını sağlamaktadır (Allen, vd., 1998). Yapılan özel gösteri ve etkinlikler turistlerin ilgilerini çekecek şekilde yeninden revize edilerek aslına uygun ancak daha fazla aksiyon içerek şekilde yeniden düzenlenmektedir. Böylece turistlerin ilgilileri daha çok artmaktadır.

Yapılan etkinlikler farklı karakterli olabilme özelliğine sahiptir. Tarımsal ürün ve gastronomi, kültür ve sanat, il ve ilçelere ait kuruluş ve kurtuluş etkinlikleri, spor, yayla, fuar ve panayırlar, ulusal bayramlar, görsel sanatlar gibi pek çok konuyla ilgili turizm etkinlikleri yapılabilmektedir. Etkinliğin yapıldığı destinasyonun tarihi ve kültürel kimliği buradaki en önemli hususların başında gelmektedir (Kızılırmak, 2006).

\section{TURIZMM VE ŞAMAN RITTÜELLERİ}

Geleneksel kimliğe sahip ve tarihten beslenen değerler ile ilgili yapılan olağan aktivite ve ritüeller zamanla etkinlik turizmi bağlamında karşılık bulmaya başlamıştır. Özellikle günümüzde yeterli düzeyde inananı olmayan inanışlara ait aktivite ve ritüeller insanlarda merak duygusu uyandırmaktadır. Bunlara ilgi duyan turistler bu etkinlikler ve ritüellere katılarak merak duygularını gidermeye çalışmaktadır. Bu durum unutulma tehlikesi altında bulunan geleneksel ve kültürel değerlerin sürdürülmesine katkı sağlamaktadır. Bu kapsamda turizmin önemli bir işlevi yerine getirdiği bilinmektedir. İnanç, mutfak, gelenek, görenek, örf ve adetlere has ve unutulma tehlikesi altında bulunan kültürel değerlere karşı oluşan merak ve duyulan ilgi bu değerlerin sürdürülmesine katkı sağlayacak yeni bir modelin ortaya çıkmasını hızlandırmıştır. Son zamanlarda Şamanizm bu kapsamda ele alınabilecek önemli bir kültürel ve tarihi kaynak olarak ön plana çıkmaya başlamıştır. 
Şamanizm eski Orta Asya ve Sibirya toplulukları tarafından inanılan bir fenomeni anlatmaktadır. $\mathrm{Bu}$ inanç kapsamında, dini törenlerle meşgul olan veya zaman zaman kendinden geçerek ruhlar dünyasına yolculuk eden ve bu konuda yetenekli olan kimseler mevcuttur. Bunlara şaman dedir. Şaman kelimesinin kökeni ve anlamıyla ilgili farklı anlamlar mevcuttur. Bunlar aşağıdaki gibi sirlanabilir (Yemenlioğlu, 2016);

- Tunguzca "saman" kelimesinden türemiştir.

- Sanskritçe "Sramana" kelimesinden türemiş olup "ruhlarla desteklenmiş adam" anlamına gelmektedir.

- Sibirya kökenli bir kelime olup "kendinden geçmiş kimse" manasında kullanılmaktadır.

Şaman kelimesinin anlamlarından da anlaşılacağı üzere Şamanizm ritüellerinde farklı şekillerde tasvir edilen bir kimse veya adam vurgusu mevcuttur. Dolayısıyla şamanların bazı sihir içeren güçlere sahip oldukları ve insanlar ile tanrılar arasında aracılık yaptıklarına inanılmaktadır. Şaman bu faaliyetleri yaparken öküz veya geyik boynuzları, üzerinde yerin ve göğün resimleriyle süslemeli özel davulu ve kuş tüyleriyle süslenmiş olan külahı vardır. Şamanın ata ruhlardan bazı özel bilgiler aldığına inanılan Şamanizm inancında, bedensel egzersizlerin oluşturduğu bazı dans ve törensel ritüeller mevcuttur (Bayat, 2006; Küçük, vd., 2018).

Şamanizm inancının dayandığ 1 törensel ve bedensel ritüeller bu ibadetin etkinlik gibi bir atmosferde geçmesine neden olmaktadır. $\mathrm{Bu}$ anlamda şamanların giydiği özel kıyafetler mitolojik formasyonları ön planda olan motifler barındırmaktadır. Ayı, geyik ve kuşlardan oluşan motiflere çok fazla yer verilir (Eliade, 1999). Çerezci (2020) bu motiflerden yırtıcı kuş motiflerinin oldukça önemli bir role sahip olduklarını vurgulamaktadır. Kıyafetlerle birlikte davul, şarkı ve danslar şamanın transa geçebilmek için yararlandığı diğer yardımcılarıdır. Davul şarkıya ve dansa kaynak oluşturması nedeniyle odaklanma için önemli bir araçtır (Drury, 1996). Şamanlar davullarını onları olağan üstü güçlerin dünyasına taşıyan binek hayvanı gibi görmektedir. Üst güçlerin (yüce ruhlar veya tanrılar) dünyasına geçen şamanlar böylece her iki dünyada da var olmaktadır. Bu işlemler esnasında şamanlar katılımcılar tarafindan izlenmektedir. Bazı sözler veya bedensel hareketlerle tanrısal güçlerle karşılaşıldığı katılımcılara hissettirilmektedir. Şarkılar ve ilahilerle tanrı ve ruhların seslerini çıkardıkları mesajını veren şamanlar bazı hayvan ve yaratıkların seslerini çıkararak onlarını hareketlerini yapmaktadır (Turan, 2010).

Şamanizm şarkı ve bedensel hareketlerden oluşan danslarıyla farklı bir inanç yapısı olarak ön plana çıkmaktadır. Şaman ritüellerindeki şarkı ve hareket eylemleri bir sembolizmi temsil etmektedir. Bu sembolizm geniş bir kültür yelpazesinin iyi bilinip tanımasını gerektirmektedir. Şamanizm ritüelleri av töreni, şifa veya fal gibi sebeplerden herhangi birinden sonra problemleri çözüme kavuşturmak ve faaliyetler için gerekçeler sunmak amacıyla bazı mitolojik kaynaklardan yararlanmaktadır (Perin, 2001).

Eski dönemlerde şamanın tanrılar veya ruhsal güçlerin bulunduğu dünyaya geçişi sırasında, bu inanca inanan insanlar şamanın etrafinda toplanmakta ve belli düzeylerde şamana beden hareketleriyle eşlik etmektedir. Günümüzde ise bu inanca mensup insanların sayısı azalsa da, ritüeller varlığını sürdürmektedir. Tarihi, kültürel ve inançsal nitelikleri nedeniyle insanların (turistlerin) ilgisini çekmektedir. Bu durumda şaman ritüellerinin kültür ve etkinlik turizmi kapsamında bir misyona sahip olup olmayacağı merak konusudur.

Günümüzde farklı coğrafyalarda turistlerin şaman ritüellerine katıldıklarına dair çalışmalar uluslararası literatürdeki yerini almaktadır. Bir Latin Amerika ülkesi olan Peru'da turistler şaman ritüellerine katılarak farklı bir turistik deneyim yaşamaktadır. Bu ritüellere Kuzey Peru ormanındaki 
ve Amazon havzasındaki önemli bir liman kenti Iquitos'ta rastlanılmaktadır. Burada bazen turistler sadece ritüelleri izlemek yerine kendilerini transa geçirebilecek maddeler kullanarak bu ritüellerin bir parçası olmayı arzu etmektedir. Bu durumda şamanlar katılımcıları turist olarak değil hasta olarak değerlendirmektedir (Prayag, vd., 2016). Böylece bölgede Şamanizm ritüelleri ile turizm arasında bir etkileşimin ortaya çıktığı gözlenmektedir. Ayahuasca denilen bitkisel maddenin kullanımı sonucu etkilenen kişiler için "inzivaya" çekilecek yerler bulunmaktadır. Bu tür inziva yerlerine gelen ziyaretçiler, "otantik", "sıra dışı", "olağanüstü" ve "alışılmadık" deneyimlerin arayışına girmektedir (Winkelman, 2005). Ayahuasca'nın etkilerinin Amazon yerli halkı tarafindan açıklanması, şamanların bu deneyimin uygulayıcıları veya kültürel aracıları olarak hareket ettiği manevi alanları ve doğaüstü güçleri içeren bir paradigmayı yansıtmaktadır (Tupper, 2008). Bu bölgenin ele alındığı çalışmalarda şaman turisti ifadesi de kullanılmaktadır.

Turizm hareketleri Ekvator' da 1980 sonrası dönemde niş turizme yönelik ulusal eğilimin bir sonucu olarak yaygınlaşmıştır. Bunun etkisiyle Şamanizm turizmi gelişmeye başlamıştır. Özellikle halüsinasyon arayışında olan turist gruplarının Ekvator'daki şaman turizmine ilgi duydukları literatürde yer almaktadır. Özellikle Latin Amerika ülkelerinde bu tür bir turistik hareketin yaygınlaşması ve popüler hale gelmesi Batı'daki turistlerin kendi ülkelerinde engellenen kişisel tatmin ve mistik deneyimler arzusuna bağlanmaktadır (Davidov, 2010).

Yerli kültürlerde enteojen turizme yönelik akademik sorgulamalar, çağdaş Şamanizm hakkındaki yazılarla sıklıkla örtüşmektedir (Lindquist 2005). Yapılan araştırmalar, küresel turizm, şaman kimliği ve şamanik kutsal yerlerin turist performansları aracılığyla inşa edilme yolları arasındaki bağlantıları araştırmaktadır. Ancak Güney Amerika ve civarında şamanik ve enteojen turizminin çeşitli yönlerini analiz eden bol miktarda akademik çalışmalara rağmen, yerli uygulayıcılar ve turistler tarafından ortak inşa edilen paralel söylemlerin teorik anlamı çok kolay oturmamaktadır. Ekvator'daki Şamanizm, bu nüanslarda önemli bir vaka çalışması sağlar. Çünkü enteojen turizminin popülaritesi, şaman kimliğinin yerel anlayışlarındaki gerilimlerin çözümlemesinde önemli katkılar sağlamıştır (Davidov, 2010)

İnsanların Şamanizm ritüellerini ilk elden deneyimleme arzusu giderek daha güçlü bir hale gelmektedir. Güney Amerika ülkelerindeki yerliler, Ayahuasca kullanımıyla birlikte "otantik" şaman ritüellerine katılım sunan merkezler kurarak bu talebe cevap vermektedir. Geleneksel Ayahuasca ritüellerini zaman zaman bir iş operasyonuna dönüştüren sözde şifacılar da (neoşamanlar) mevcuttur (DuBois 2009). Ayahuasca kullanan turistler genellikle kendilerini gerçekleştirme ve statü arzusuyla yönlendirilen bir deneyim yaşamaktadır. Bu turistler sosyal geleneklerin ve paylaşılan değerlerin eksikliği, düşük benlik saygısı veya ülkelerindeki alternatif tedavilerin erişilemezliği gibi hayatlarında ve kültürlerinde eksik olan bir takım olguları telafi etme arayışındadır. Bunu da Şamanizm ritüelleri, Ayahuasca ve halüsinasyon gibi araç ve yöntemlerle gerçekleştirmektedir. $\mathrm{Bu}$ faaliyetlerin güvenle yapımının sağlanması önemlidir. Çünkü bu uygulamalarda turistlerin zarar görme riski bulunmaktadır (Kavenska ve Simonova, 2015; Fotiou, 2020).

Bir dizi etkinliğin yanında Şamanizm ritüellerinin kültürel mirasın korunmasına aracılık eden kültürel bir niteliğe de sahip olduğu söylenebilir. Şaman turizmi kapsamında yapılan organize ve rehberli turlar, turist performansının sosyal eylem biçimlerinin çağdaş, etnik ve dini kimlikleri nasıl şekillendirdiğine dair paradigmatik bir öngörü sunmaktadır. Bu durumun şamanik turizm biçiminin kültürel mirasın daha fazla eklemlenmesiyle (küçülmesinden ziyade) sonuçlandığı söylenebilir. Çok yönlü Şamanizmin yeniden canlandırma sürecinin bir parçası olarak kutsal yerlerin kültürlerarası üretimine odaklanma, Şamanizm'in "gerçek bir dünya dini" olarak yeniden icat edilme ve kutsal 
yerleri "tapınakların" eşdeğerleri haline getirme gibi unsurlar turizm-şaman ritüellerinin ortak paydaları olarak öne çıkmaktadır (Bernstein, 2008).

\section{SONUÇ VE TARTIŞMA}

Dünyanın son y1llarda global bir kimlik kazanıyor olması, aynı zamanda ortak ve standart yaşam kalıplarının ortaya çıkmasını hızlandırmıştır. Bu durum giderek yaygın bir gelenek haline gelmektedir. Bu gelişme eski, geleneksel, otantik ve tarihi bazı olay ve olgulara olan merakı ve duyulan ilgiyi artırmaktadır. İnsanlar katıldıkları turizm faaliyetleriyle bu meraklarını giderme ve ilgilerine karşı1lık bulma arayışına girmektedir. Örneğin; Fast-Food ile standart hale gelen beslenme kültürü, insanların yerel mutfaklara ve yöresel yiyeceklere duyulan özlemlerini artırmaktadır. Bu noktada gastronomi turizmi devreye girmektedir. Böylece turizm hem turistlerin özlemlerini gidermekte hem de kültürel ve otantik değerlerin sürdürülebilirliğine katkıda bulunmaktadır.

Son yıllarda ön plana çıkan ve turizm faaliyetleri için kaynak teşkil eden önemli bir eski ve otantik uygulama da şaman ritüelleridir. Şamanik turizm adı altında özellikle Güney Amerika ülkelerinde yaygın olarak varlığını sürdüren bir uygulama mevcuttur. Ancak $\mathrm{Bu}$ turizm çeşidinin bazı maddelerin kullanımını teşvik eden yapısı ve halüsinasyon halini içermesi nedeniyle çok yaygın olması mümkün değildir. Talep çeken bir uygulama olsa da, bu durum eleştirilebilir. Dolayısıyla geliştiği bölgeler için bir niş pazar olarak kalmaktadır. Bunun aksine ilginç ve kendine özgü bazı ritmik hareketleri içermesi nedeniyle şaman ritüellerinin etkinlik turizmi bağlamında ele alındığ1 bilinmektedir. İnsanlar izleyici olarak şaman ritüellerinin gerçekleştiği bölgelere giderek bu kültürü tanımayı amaçlamaktadır. Ayrıca eski bir inancın uygulamalarını sürdürmesi nedeniyle de önemli bir kültürel öğe olarak kültür turizmi kapsamında da işlenebilmektedir.

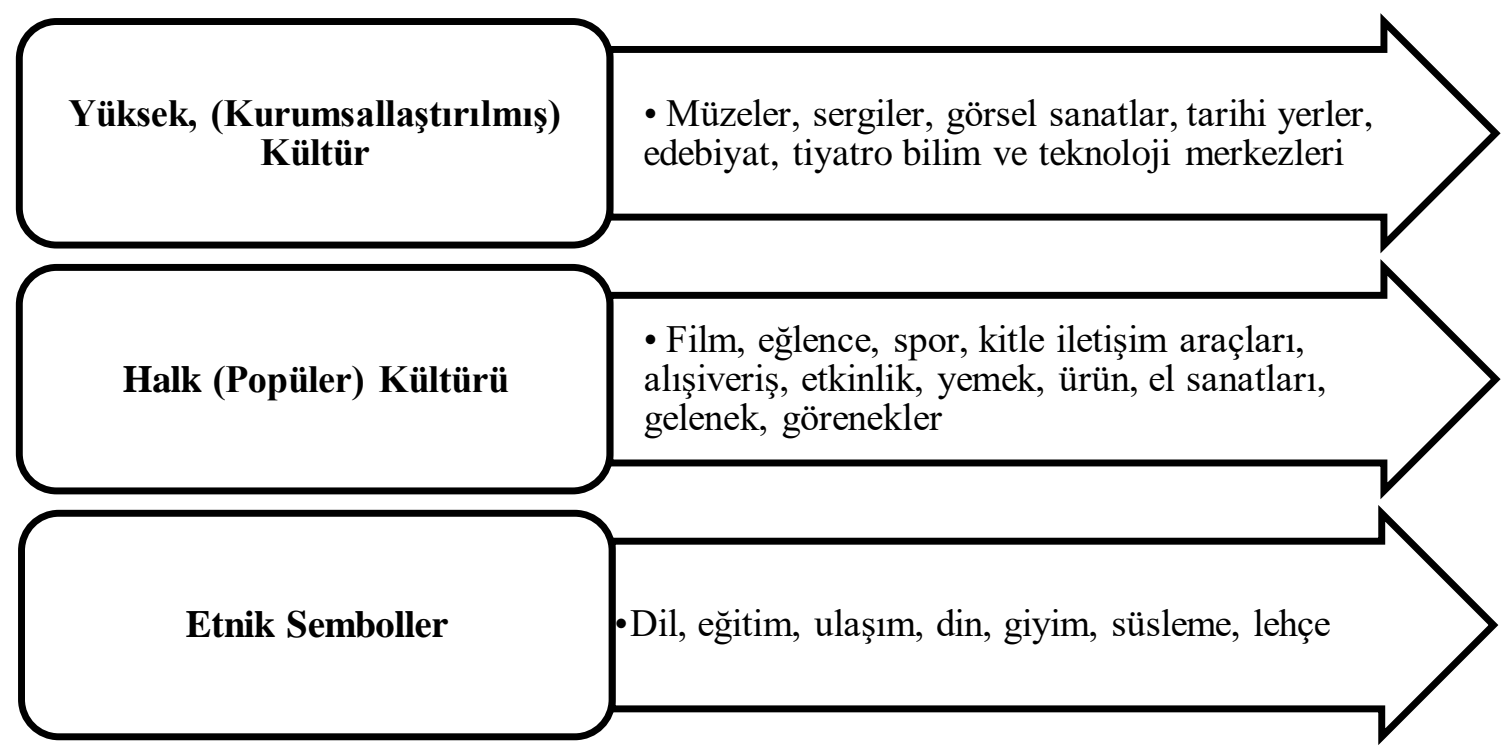

Şekil 2. Kültür Turizminin Sınıflandırılması

Kaynak: (Fagence, 2003)'den geliştirilmiştir.

Kültür turizminin sınıflandırmasını bulunduğu Şekil 2 incelendiğinde, turizme konu olan kültürel unsurların aile, dil, din, spor ve etkinlikler, beslenme, bilim ve edebiyat gibi çok geniş ölçüde değerlendirildiği anlaşılmaktadır. Şamanizm ritüelleri incelendiğinde, ilgili ritüellerin yüksek (kurumsallaştırılmış kültür, halk (popüler) kültürü ve etnik sembollerin tamamı için kabul gören bir 
kimliğe sahip oldukları söylenebilir. Ritüellerin sahip olduğu tarihi karakter, görsel sanatları içeren yapısı ve müzelerdeki görselleriyle yüksek (kurumsallaştırılmış) kültürü temsil ettikleri söylenebilir. Bir dizi etkinlik içermesi nedeniyle halk kültürü, inanç sistemi ve giyimle olan yakın ilişkisi nedeniyle de etnik sembolleri temsil ettikleri söylenebilir. Bu kapsamda şaman ritüellerinin kültür ve etkinlik turizmi bağlamında değerlendirilmesi gerektiği söylenebilir.

$\mathrm{Bu}$ çalışma spesifik bir konuda önemli tespitler ortaya koysa da, ampirik bulgularla desteklenmemesi nedeniyle bazı en önemli kısıtlar içermektedir. Ancak gerek konuyla ilgili ritüellerin çok yaygın olmaması, gerekse de bu turizm çeşidinin niş bir pazar niteliği taşıması böyle bir çalışma sürecini zorunlu kılmıştır. İleride bu konuyla ilgili ampirik çalışmalar yapılabilir. Ayrıca Şaman ritüellerinin etkinlik turizmi bakımından gelişmesi durumunda, bu etkinliklere katılma noktasında turistlerin algı ve tutumları araştırılabilir.

\section{KAYNAKÇA}

Akgül, O. (2003). Turistik Ürün Çeşitlendirmesi Kapsamında Kültür Turizmi, Aphrodisias-Geyre Örneği. Yayınlanmamış Yüksek Lisans Tezi, Adnan Menderes Üniversitesi Sosyal Bilimler Enstitüsü, Aydin.

Akten M. \& Akten, S. (2011), Rekreasyon Potansiyellerinin Belirlenmesine Yönelik Bir Model Yaklaşımı: Gülez Yöntemi. I. Ulusal Sarıgöl İlçesi ve Değerleri Sempozyumu, 17-19 Şubat 2011, Sarıgöl

Allen, J., O'toole, W., Harris, R., \& McDonnell, I. (2008). Festival and Special Event Management. Brisbane: John Wiley ve Sons Incorporated.

Bakır, Z. N., \& Çelik, H. C. (2020). Kitle ve Kültür Turizmi Bağlamında JollyTur ve EtsTur Seyahat Acentelerine Ait İnternet Reklamlarının İçerik Analizi. Akdeniz Üniversitesi İletişim Fakültesi Dergisi, (33), 318-337.

Bakır, Z. N., \& Çelik, H. C. (2020). Kitle ve Kültür Turizmi Bağlamında JollyTur ve EtsTur Seyahat Acentelerine Ait İnternet Reklamlarının İçerik Analizi. Akdeniz Üniversitesi İletissim Fakültesi Dergisi, (33), 318-337.

Bayat, F. (2004). Türk Şaman Metinleri. Efsaneler ve Memoratlar, Ankara: Piramit Yayınları

Can, E. (2015). Boş Zaman, Rekreasyon ve Etkinlik Turizmi İlişkisi. İstanbul Sosyal Bilimler Dergisi, (10), $1-17$.

Çerezci, J. Ö. O. (2020). Türk Sanatında Üç Dişli Başlığa Sahip Şamanlar ve Savaşçılar. Sanat Tarihi Dergisi, 29(2), 765-781.

Davidov, V. M. (2010). Shamans and shams: The discursive effects of ethnotourism in Ecuador. The Journal of Latin American and Caribbean Anthropology, 15(2), 387-410.

Drury, N. (1996). Şamanizm ve Şamanlığın Öğeleri. E. Şimşek (Çev.), İstanbul: Okyanus Yayıncılık

DuBois, T. A. (2009). An introduction to shamanism (p. 160). Cambridge: Cambridge University Press.

Eliade, M. (1999). Şamanizm. İ. Birkan (çev.), İstanbul: İmge Kitabevi.

Emekli, G. (2006). Coğrafya, kültür ve turizm: kültürel turizm. Ege Coğrafya Dergisi, 15(1-2), 51-59.

Eryılmaz, S. S. \& Cengiz, H. (2012). Mega Etkinliklerin Kent Mekânına Ekonomik Yansımaları, Formula 1 Örneği. Sigma, 4(Özel Sayı), 77-96

Fagence, M. (2003). Turism In Destination Communities, (Edited By S. Singh, D. J. Timothy And R. K. Dowling), Cambridge:Cabi Publishing. 
Fotiou, E. (2010). From medicine men to day trippers: shamanic tourism in Iquitos, Perus (pp. 136-138). University of Wisconsin-Madison.

Fotiou, E. (2020). The Importance of Ritual Discourse in Framing Ayahuasca Experiences in the Context of Shamanic Tourism. Anthropology of Consciousness, 31(2), 223-244.

Getz, D. (1997). Event management ve event tourism. New York: Cognizant Communication Corporation

Huh, J. (2002). Tourist satisfaction with cultural/heritage sites: The Virginia Historic Triangle (Doctoral dissertation, Virginia Tech).

Kavenská, V., \& Simonová, H. (2015). Ayahuasca tourism: Participants in shamanic rituals and their personality styles, motivation, benefits and risks. Journal of Psychoactive Drugs, 47(5), 351-359.

Kızılırmak, İ. (2006). Türkiye'de Düzenlenen Yerel Etkinliklerin Turistik Çekicilik Olarak Kullanılmasına Yönelik Bir İnceleme. Manas Üniversitesi Sosyal Bilimler Dergisi, 8(15), 181-196.

Kousis, M. (2000). Tourism and the environment: A social movements perspective. Annals of Tourism Research, 27(2), 468-489.

Kozak, M. A. \& Bahçe, S. (2009), Özel İlgi Turizmi, Ankara: Detay Yayıncılık

Kozak, M., Evren, S. \& Çakır, O. (2013). Tarihsel Süreç İçinde Turizm Paradigması. Anatolia Turizm Araştırmaları Dergisi, 24(1), 7-22.

Küçük, A., Tümer, G. \& Küçük, M. A. (2018). Dinler Tarihi. Ankara: Berikan Kitapevi

Lindquist, G. (2005). Healers, leaders and entrepreneurs: shamanic revival in southern Siberia. Culture and Religion, 6(2), 263-285.

Mallen, C., \& Adams, L. J. (2008). Sport, Recreation and Tourism Event Management: Theoretical and Practical Dimensions. New York: Routledge Press

McKercher, B., ve Du Cros, H. (2002). Cultural Tourism: The Partnership between Tourism and Cultural Heritage Management. New York: Routledge Press

Perin, M. (2001) Şamanizm. B. Abraş (Çev.), İstanbul: İletişim Yayınları

Prayag, G., Mura, P., Hall, C. M. \& Fontaine, J. (2016). Spirituality, drugs, and tourism: tourists' and shamans' experiences of ayahuasca in Iquitos, Peru. Tourism Recreation Research, 41(3), 314-325.

Şahin, C. K., Akten, S. \& Erol, U. E. (2009). Eğirdir Meslek Yüksekokulu Öğrencilerinin Rekreasyon Faaliyetlerine Katılımlarının Belirlenmesi Üzerine Bir Çalışma. Artvin Çoruh Üniversitesi Orman Fakültesi Dergisi, 10 (1):62-71

Şengel, Ü. (2019). Türkiye'nin Turizm Talebini Etkileyen Faktörlerin Sosyo-Ekonomik Açıdan Ampirik Olarak Değerlendirilmesi, Yayınlanmamış Doktora Tezi, Sakarya Uygulamalı Bilimler Üniversitesi, LEE, Sakarya

Tassiopoulos, D. (2005). Event Management: A Professional and Developmental Approach. 2nd Editon, South Africa :Juta Academic.

Tayfun, A., \& Arslan, E. (2013). Festival Turizmi Kapsamında Yerli Turistlerin Ankara Alışveriş Festivali’nden Memnuniyetleri Üzerine Bir Araştırma. Işsletme Araştırmaları Dergisi, 5(2), 191206.

Toskay, T. (1993). Turizm. İstanbul: Der Yayınları.

Tupper, K. W. (2008). The globalization of ayahuasca: Harm reduction or benefit maximization? International Journal of Drug Policy, 19, 297-303. 
Turan, F. A. (2010). Şaman Ritüellerinden Alevi Semahlarına Esrarlı Yolculuk. Türk Kültürü ve Hacı Bektaş Veli Araştırma Dergisi, (56), 153-162

Uygur, S. M. \& Baykan, E. (2007). Kültür turizmi ve turizmin kültürel varlıklar üzerindeki etkileri. Gazi Üniversitesi Ticaret ve Turizm Eğitim Fakültesi Dergisi, (2), 30-49.

Williams, R. (2018) Anahtar Sözcükler. S. Kılıç (Çev.), İstanbul: İletişim Yayınları

Winkelman, M. (2001). Alternative and traditional medicine approaches for substance abuse programs: A shamanic perspective. International Journal of Drug Policy, 12, 337- 351.

Yemenlioğlu, M. M. (2016). Dinler Tarihi. İstanbul: Gelenek Yayıncılık 